\title{
Community Pharmacy Customers' Knowledge and Perception towards Self-Medication with Over-the-Counter Drugs: A Cross-Sectional Study in Asmara, Eritrea
} \author{
Tesfai $^{1}$ and Mulugeta Russom ${ }^{3}$ \\ ${ }^{1}$ School of Pharmacy, Asmara College of Health Sciences, Eritrea \\ ${ }^{2}$ Department of Statistics, College of Sciences, Eritrean Institute of Technology, Mai Nefhi, Eritrea \\ ${ }^{3}$ National Medicine and Food Administration, Ministry of Health, Eritrea
}

Biruck Woldai Abraha1*, Eyasu H Tesfamariam², Sirak Tesfamariam¹, Ghide Kaleab ${ }^{1}$, Samson Berhane ${ }^{1}$, Dawit

Submission: October 21, 2021; Published: November 02, 2021

*Corresponding author: Biruck Woldai Abraha, School of Pharmacy, Asmara College of Health Sciences, Eritrea, Email:brookpharm@gmail.com

\begin{abstract}
Background: With an increase in the number of over the counter (OTC) drugs, practice of self-medication- that is influenced by the knowledge and attitude- is becoming common worldwide.

Objective: The aim was to assess the knowledge and attitude of self-medication with OTC drugs and their socio-demographic determinants.

Method: A descriptive cross-sectional study was conducted among 609 community pharmacy customers in Asmara between August and September 2017. Two-stage cluster sampling and a pre-tested structured questionnaire were used to collect the data through face-to-face exit interviews. Descriptive analysis, independent sampled-test, ANOVA (with LSD post-hoc) test, and ANCOVA test were performed using SPSS (Version 22).
\end{abstract}

Result: Most of the respondents were aware that OTC drugs should only be used to treat minor diseases and injuries and found to be knowledgeable enough in the use of OTC drugs after expiry date and during pregnancy and handling adverse effects. In general, the attitude of the respondents was positive, and at multivariate level it was found to be significantly affected by the knowledge ( $p<0.0001)$, marital status ( $p$ $=0.002)$, educational level $(p=0.002)$, and chronic illness $(p=0.039)$. Respondents without chronic illness $(M=37.20$, SD 3.69) had a higher attitude than those with chronic illness $(M=36.45$, SD 3.51). The difference in attitude was also found to be significant between respondents with knowledge above average $(M=37.57$, SD 3.47) and below average $(M=36.39$, SD 3.76). Respondents with higher education and married had higher attitude scores across their respective categories.

Conclusion: Overall, the knowledge and attitude of the respondents towards self-medication with OTC drugs was satisfactory except on the use of these drugs in elderly and lactating women, and a poor attitude towards drug interactions.

Keywords: Self Medication; Over the Counter Drugs; Knowledge; Attitude; Community Pharmacies; Asmara

\section{Introduction}

Self-medications defined as the selection and use of medicines / medicinal products including herbal and traditional products by individuals to treat self-recognized illness or symptoms, or the intermittent or continued use of a medication prescribed by a physician for chronic or recurring diseases or symptoms [1]. The practice of self-medication is becoming more common worldwide with an incidence higher in developing countries [1-3].

Although OTC drugs are meant for the purpose of selfmedication and believed to be safe and effective, indeed they are not totally safe. They can mask the underlying disease, may cause several adverse effects if used inappropriately [4], and the risks of interactions and adverse reactions could be increased in conditions when medical aid should have been sought $[5,6]$. There is also a potential for misuse and abuse of such products [7-9] due to their unregulated availability in the market [10]. A very common observation of self-medication seeking behavior in Asmara (a capital city of Eritrea) community pharmacies accompanied by poor knowledge has been reported [11]. In Eritrea, to minimize the negative outcomes of self-medication and 


\section{Juniper Online Journal of Public Health}

misuse/abuse of drugs, medicines are legally classified as OTC, pharmacy medicine, prescription-only medicine, and controlled substances[unpublished]. As the number of non-prescription medications is growing [12], information regarding these medications and their usage at a societal level has an important role for safer use. Some studies suggested that knowledge, which subsequently affects attitude, of customers toward nonprescription medications is not up to the level that promotes rational use of these drugs [13]. Another study, in contrast, suggested that consumers had a positive attitude towards selfmedication influenced by their good medical knowledge on these medications [14]. Thus, assessing consumers' knowledge and attitude towards self-medication with OTC drugs is very important as it influences the practice pattern of a community. Moreover, the result may have an impact on developing strategies that would be deployed in addressing any poor knowledge and attitude outcomes. The main aim of this work was, therefore, to assess the knowledge and attitude of self-medication with OTC drugs and their socio-demographic determinants.

\section{Methods}

\section{Study design and setting}

We followed the methods of Sirak Tesfamariam et al [15]. A descriptive cross-sectional study was conducted in 20 selected community pharmacies in Asmara between $28^{\text {th }}$ August and $21^{\text {st }}$ September 2017 for a period of 20 days.

\section{Source and study population}

Residents of Asmara were the source of population for this study. As per the Administration of Central Region of Eritrea database, in 2017, the population of Asmara was 427,183 which were served by 48 community pharmacies corresponding to 8900 residents per community pharmacy. Customers aged 18 years and above, who visited the community pharmacies to purchase medicine(s) during the study period and who were willing to participate were considered as a study population. Customers who couldn't communicate in either Tigrigna (Eritrea's national language) or English, who were deaf or mentally unable to communicate were excluded.

\section{Sampling design}

Since the study was done in a community with a large and widely scattered source population, two-stage cluster sampling was used. The list of community pharmacies in Asmara was first obtained from the National Medicines and Food Administration. Managers of the respective community pharmacies were requested to provide estimates of the average number of customers per day. Of the non-systematically arranged 48 community pharmacies, 20 sites were randomly selected by probability proportionate to size. The number of subjects to be interviewed at each study site was allocated proportionally to the estimated average number of customers per day. Finally, every $36^{\text {th }}$ customer was interviewed at each study site.

\section{Sample size estimation}

The sample size was calculated by using the single proportion formula without correction for continuity: $\mathrm{n}=\mathrm{Z}^{2 *} \mathrm{P}(1-\mathrm{P}) / \mathrm{d}^{2}[16]$. The total sample size (n) was calculated using the following assumptions: $p$ (proportion $=0.5$, for no other similar studies were conducted previously), Z (standardized score for a $95 \%$ confidence level=1.96), and $d$ (degree of precision=0.05 in proportion of one). After adjustment for the possible non-response (5\% rate) and design effect (1.5), a total of 609 participants were taken in this study.

\section{Data collection tool and approach}

A structured questionnaire consisting of three sections was constructed upon a review of similar studies [17-20]. The questionnaire was designed to capture data on socio-demographic and background characteristics, knowledge, and attitude towards self-medication with OTC drugs.

Knowledge was measured using 10 questions designed to assess the general awareness of the respondents about OTC drugs and their knowledge regarding indications, contraindications, adverse effects and usage of those drugs. While assessing determinants, knowledge was categorized into two groups (Knowledge below and above average), where 20 was the maximum score.

Attitude was measured through 11 questions related to safety, efficacy, accessibility, and usage of OTC drugs in a five-point Likert scale. The minimum and maximum ideal attitude scores were 11 and 55 respectively. Increase in raw score indicates an increase in positive attitude.

After explaining the aims of the study and obtaining written informed consent, face to face exit-interviews were conducted using a structured questionnaire.

\section{Questionnaire pre-test}

A pre-test was conducted among 30 participants on the $9^{\text {th }}$ and $10^{\text {th }}$ of August 2017, for checking the comprehensibility of the questions at six randomly selected community pharmacies which were not included in the main study. After the pre-test, necessary modifications were made in the final version of the questionnaire.

\section{Statistical analysis}

Data were double entered in CSPro (Version 7.0) and analyzed using SPSS (Version 22). Descriptive analysis of the sociodemographic variables, knowledge on OTC drugs, and attitude of the respondents toward OTC drugs was done using frequency (percent), mean (SD), and median (IQR), as appropriate. Independent sampled-test and ANOVA (with LSD post-hoc) test were used to find out the difference in attitude towards OTC drugs scores across the categories of demographic variables. Variables found to be significant at the univariate level were further considered at multivariate analysis using ANCOVA test in order to control the effect of potential confounders. Results were deemed to be statistically significant at $\mathrm{p}<0.05$. 


\section{Results}

\section{Socio-demographic and background characteristics}

Out of the 609 participants, 587 completed the interview successfully yielding a response rate of $96.4 \%$. Three hundred and eighty-one $(64.9 \%)$ of the respondents were males and 206 $(35.1 \%)$ were females and the median age was 37 years (IQR=24). Many of the respondents were married (60.1\%), aged between 25 and 34 years (26.7\%), governmental employees (37.6\%), and $72.1 \%$ had no known chronic illness. The educational level was measured in years (attended to formal education) and one-third (33.6\%) of the respondents achieved their higher education. The respondents' socio-demographic information is shown in (Table 1).

Table 1: Socio-demographic characteristics of the espondents $(n=587)$.

\begin{tabular}{|c|c|c|}
\hline Variables & Frequency & Percent \\
\hline \multicolumn{3}{|l|}{ Gender } \\
\hline Male & 381 & 64.9 \\
\hline Female & 206 & 35.1 \\
\hline \multicolumn{3}{|c|}{ Age $($ Median=37, IQR =24, Range $=18$ to 95 ) } \\
\hline 18 to 24 & 113 & 19.3 \\
\hline 25 to 34 & 157 & 26.7 \\
\hline 35 to 44 & 118 & 20.1 \\
\hline 45 to 59 & 118 & 20.1 \\
\hline 60 or above & 81 & 13.8 \\
\hline \multicolumn{3}{|l|}{ Marital status } \\
\hline Married & 353 & 60.1 \\
\hline Single & 196 & 33.4 \\
\hline Divorced & 22 & 3.7 \\
\hline Widowed & 16 & 2.7 \\
\hline \multicolumn{3}{|c|}{ Educational level (Median=12, IQR=4, Range $=0$ to 20) } \\
\hline Elementary or below & 44 & 7.5 \\
\hline Junior & 68 & 11.6 \\
\hline Secondary school & 278 & 47.4 \\
\hline Higher Education & 197 & 33.6 \\
\hline \multicolumn{3}{|l|}{ Occupation } \\
\hline Governmental services & 221 & 37.6 \\
\hline Private services & 83 & 14.1 \\
\hline Self-employed & 134 & 22.8 \\
\hline Unemployed & 29 & 4.9 \\
\hline Student & 47 & 8 \\
\hline Housewife & 73 & 12.4 \\
\hline \multicolumn{3}{|l|}{ Chronic illness } \\
\hline Yes & 164 & 27.9 \\
\hline No & 423 & 72.1 \\
\hline \multicolumn{3}{|l|}{ Religion } \\
\hline Christian & 504 & 85.9 \\
\hline Muslim & 81 & 13.8 \\
\hline Others* & 2 & 0.3 \\
\hline
\end{tabular}

Others* contain Jehovah's witness and Atheist.

\section{Respondents' knowledge on OTC drugs}

The percentage distribution of respondents regarding the correct knowledge of OTC drugs is shown in (Table 2). Almost 92\% of the respondents had general knowledge regarding the existence of OTC drugs and $80.9 \%$ of the respondents were aware that OTC drugs should only be used to treat minor diseases and injuries. Most of the respondents were found to be knowledgeable enough in the use of OTC drugs after expiry date and during pregnancy. Comparatively, their knowledge regarding consumption of OTC drugs during breastfeeding and in elderly was low. Knowledge of the respondents on adverse effects that could be caused by the use of OTC drugs was below average (47.7\%). Even though their knowledge on adverse effects was slightly low, as described above, their response to a question addressing what one should do if suspected adverse effect(s) is/are seen was high. Most of the respondents, 96.9\%, answered that one should not continue taking the drug if any adverse effect(s) is/are seen and $91.7 \%$ answered that one should report to a doctor or a pharmacist if he/she notices any adverse effect. With respect to the knowledge about possible drug-drug interaction, $74.1 \%$ had knowledge on this matter and responded correctly that all OTC drugs are not safe when taken along with prescribed drugs.

The median knowledge score was found to be 15 out of 20 . This median score was used to classify the knowledge on OTC drugs into "Knowledge above" and "Knowledge below" the average, and these categories were used to find further associations. Accordingly, 307 (52.3\%) were categorized as above average and the remaining $280(47.7 \%)$ as below average.

\section{Respondents' attitude towards OTC drugs}

Though attitude was assessed using a five-point Likert scale, descriptive results are presented in three categories as "Disagree", "Neither agree nor disagree", and "Agree", to make it comprehensible. As depicted in (Table 3), of the 587 respondents, $61.7 \%$ disagreed that OTC drugs commonly used for selfmedication are safe and $57.9 \%$ had an attitude that they are cheaper and convenient. In the overdose usage of paracetamol, $84.2 \%$ believed that it is a powerful poison.

The respondents' attitude towards drug-drug interaction was higher in the agree choice. Forty-four percent agreed that OTC drugs can modify or alter the action of another drug, whereas $22.5 \%$ were neutral. Most of the respondents (90.1\%) opposed the usage of all OTC drugs during pregnancy. Likewise, $86.2 \%$ of the respondents agreed that OTC drugs are affected by storage conditions, like temperature, moisture, and direct sunlight. The majority of the respondents (69.8\%) believed that analgesics, specifically NSAIDs when taken on an empty stomach, can cause gastritis, whereas $7.2 \%$ did not believe that such side-effect could be caused by the above-mentioned drug class.

Approximately $78 \%$ and $62 \%$ of the respondents believed that liquid medicines and eye/ear drops should not be used after one month of opening respectively. Besides, two-third (68\%) of 


\section{Juniper Online Journal of Public Health}

the participants felt that it is better not to take OTC $\operatorname{drug}(\mathrm{s})$ when are safe, but they would seek physician's advice before using it. they are sick and $94 \%$ of the respondents believed that OTC drugs

Table 2: Percentage distribution of respondents on the correct knowledge regarding OTC drugs $(n=587)$.

\begin{tabular}{|c|c|c|}
\hline No. & Questions & Correct Knowledge (\%) \\
\hline 1 & Medicines are always used on the prescription of a doctor. & 91.8 \\
\hline 2 & All OTC drugs are safe and effective. & 47.9 \\
\hline 3 & OTC drugs are used for treating minor illnesses or injuries. & 80.9 \\
\hline 4 & OTC drugs are approved for self-care. & 41.7 \\
\hline \multirow{5}{*}{5} & Which of the following drugs fall under OTC drugs? & \\
\hline & Antipyretics & 60.3 \\
\hline & Anti-cold & 48.4 \\
\hline & Analgesics & 84.3 \\
\hline & Anti-microbial & 78.2 \\
\hline 6 & OTC drugs could not be used after their expiry date. & 96.4 \\
\hline 7 & OTC drugs can sometimes cause side-effect(s) & 47.7 \\
\hline \multirow{6}{*}{8} & While using OTC drugs, caution should be taken mostly in: & \\
\hline & Pregnancy & 92.2 \\
\hline & Lactation & 58.1 \\
\hline & Elderly & 45 \\
\hline & Children & 86.4 \\
\hline & Adolescents & 82.8 \\
\hline \multirow{5}{*}{9} & If suspected adverse effect(s) is/are seen, then one should: & \\
\hline & Immediately stop using the drug & 46.2 \\
\hline & Not take low dose until adverse effect(s) subside & 96.3 \\
\hline & Not continue taking the drug regardless of the adverse effect(s) & 96.9 \\
\hline & Report to Doctor or Pharmacist & 91.7 \\
\hline 10 & All OTC drugs when taken along with prescribed drug are not safe. & 74.1 \\
\hline
\end{tabular}

Table3: Percentage distribution of respondents by their attitude on OTC drugs $(n=587)$.

\begin{tabular}{|c|c|c|c|c|}
\hline \multirow[b]{2}{*}{ No. } & \multirow[b]{2}{*}{ Questions } & \multicolumn{3}{|c|}{ Percent } \\
\hline & & Disagree & $\begin{array}{l}\text { Neither Agree } \\
\text { Nor disagree }\end{array}$ & Agree \\
\hline 1 & OTC drugs that are used for self-medication are safe. & 61.7 & 8.7 & 29.6 \\
\hline 2 & OTC drugs are cheaper and convenient. & 32.2 & 9.9 & 57.9 \\
\hline 3 & Paracetamol in overdose is a powerful poison. & 6.8 & 9 & 84.2 \\
\hline 4 & OTC drugs can modify or alter the action of another drug. & 33.4 & 22.5 & 44.1 \\
\hline 5 & All OTC drugs can be used in case of pregnancy. & 90.1 & 6.1 & 3.7 \\
\hline 6 & Pain killers when taken on an empty stomach does not cause gastritis. & 69.8 & 23 & 7.2 \\
\hline 7 & $\begin{array}{c}\text { OTC drugs are not affected by storage conditions, like temperature, moisture and } \\
\text { direct sunlight. }\end{array}$ & 86.2 & 6.6 & 7.2 \\
\hline 8 & Liquid medicines could be used when opened after one month. & 77.5 & 11.2 & 11.2 \\
\hline 9 & Eye/Ear drops could be used after one month of opening. & 62.2 & 20.6 & 17.2 \\
\hline 10 & It is better I don't take OTC drug when I am ill. & 26.9 & 5.1 & 68 \\
\hline 11 & OTC drugs are safe but would seek a physician advice before using it. & 3.6 & 2.4 & 94 \\
\hline
\end{tabular}




\section{Juniper Online Journal of Public Health}

\section{Factors associated with the attitude towards OTC drugs}

\section{Univariate analysis of attitude towards OTC drugs}

The possible difference in the attitude scores among various independent variables with two categories was performed using independent sample t-test (Table 4). The result indicated that males $(M=37.25, S D=3.62)$ have significantly higher $(\mathrm{p}=0.029)$. attitude score than females $(M=36.56, S D=3.67)$. Similarly, respondents without chronic illness $(M=37.20$, SD 3.69) were found to have significantly ( $p=0.038$ ) higher attitude than those with chronic illness ( $M=36.45$, SD 3.51). The difference in attitude was also found to be significant $(\mathrm{p}<0.0001)$ between respondents with knowledge above average ( $M=37.57$, SD 3.47) and below average ( $M=36.39$, SD 3.76). On the other hand, there was no significant difference in attitude score between the categories of religion $(p=0.613)$ and categories of ethnicity $(p=0.620)$.
One-way ANOVA was also used to investigate the difference in attitude scores for those independent variables having more than two categories (Table 5). The result revealed that there was a significant difference in attitude scores towards OTC drugs across categories of educational level $(\mathrm{p}<0.0001)$. An increase in a positive attitude with an increase in educational level ( $\mathrm{p}$-trend $<0.0001$ ) was also observed. Moreover, a significant difference in attitude among categories of marital status $(p=0.029)$ was found. But there was no significant difference in attitude among the occupational status of the respondents ( $p=0.081)$.

LSD post hoc analysis revealed that there was a significantly higher attitude in married than single respondents $(\mathrm{p}=0.009)$. Besides, a significant difference in attitude between respondents with higher education and elementary or below $(\mathrm{p}=0.009)$, higher education and junior $(\mathrm{p}<0.0001)$, and higher education and secondary school $(p=0.002)$ educational level were observed.

Table 4: Difference in attitude of respondents by socio-demographic characteristics using independent t-test.

\begin{tabular}{|c|c|c|c|c|}
\hline Variable & M (SD) & Diff & $95 \% \mathrm{CI}$ & P-Value \\
\hline \multicolumn{5}{|l|}{ Gender } \\
\hline Male & 37.25 (3.62) & 0.69 & $(0.07,1.31)$ & 0.029 \\
\hline Female & 36.56 (3.67) & & & \\
\hline \multicolumn{5}{|l|}{ Chronic illness } \\
\hline No & $37.20(3.69)$ & 0.71 & $(0.04,1.37)$ & 0.038 \\
\hline Yes & $36.45(3.51)$ & & & \\
\hline \multicolumn{5}{|l|}{ Religion } \\
\hline Christian & $36.98(3.56)$ & -0.22 & $(-1.08,0.64)$ & 0.613 \\
\hline Muslim & $37.20(4.20)$ & & & \\
\hline \multicolumn{5}{|l|}{ Ethnicity } \\
\hline Tigrigna & 36.98 (3.59) & -0.26 & $(-1.30,0.77)$ & 0.62 \\
\hline Other ethnicities & $37.25(4.25)$ & & & \\
\hline \multicolumn{5}{|l|}{ Knowledge } \\
\hline Below average & $36.39(3.76)$ & -1.19 & $(-1.77,-0.60)$ & $<0.0001$ \\
\hline Above average & 37.57 (3.47) & & & \\
\hline
\end{tabular}

Note: $\mathrm{M}=$ Mean, $\mathrm{SD}=$ Standard Deviation, $\mathrm{Cl}=$ Confidence Interval, Diff = Difference in mean

Table 5: Difference in the attitude of respondents by socio-demographic characteristics using ANOVA.

\begin{tabular}{|c|c|c|c|c|}
\hline Variable & M (SD) & F Value & P-Value & P-Trend \\
\hline \multicolumn{5}{|l|}{ Marital status } \\
\hline Married & $37.37(3.60)$ & 3.02 & 0.029 & - \\
\hline Single & $36.52(3.73)$ & & & \\
\hline Divorced & 36.05 (3.39) & & & \\
\hline Widowed & $36.38(3.34)$ & & & \\
\hline \multicolumn{5}{|l|}{ Educational level } \\
\hline Elementary or below & $36.14(3.50)$ & 6.26 & $<0.0001$ & $<0.0001$ \\
\hline Junior & $36.04(3.09)$ & & & \\
\hline Secondary school & $36.79(3.50)$ & & & \\
\hline Higher Education & $37.83(3.92)$ & & & \\
\hline
\end{tabular}




\begin{tabular}{|c|c|c|c|c|}
\hline \multicolumn{2}{|l|}{ Occupation } & \multicolumn{1}{|l|}{1.97} & 0.081 & - \\
\hline Governmental & $37.49(3.71)$ & & & \\
\hline Private services & $36.60(3.28)$ & & & \\
\hline Self-employed & $36.58(3.55)$ & & & \\
\hline Unemployed & $37.31(3.08)$ & & & \\
\hline Student & $36.15(4.49)$ & & & \\
\hline Housewife & $37.21(3.54)$ & & & \\
\hline
\end{tabular}

Note: $\mathrm{M}=$ Mean, $\mathrm{SD}=$ Standard Deviation.

\section{Multivariate analysis of attitude towards OTC drugs}

Multivariate analysis using ANCOVA test showed that knowledge $(\mathrm{p}<0.0001)$, marital status $(\mathrm{p}=0.002)$, educational level ( $p=0.002)$, and chronic illness ( $p=0.039$ ) had significant effect on attitude towards OTC drugs (Table 6). However, after controlling the effect of the other significant factors at univariate analysis, gender $(p=0.206)$ was not a significant determinant of attitude towards OTC drugs. The factor which was found to have the highest contribution in explaining the variations in attitude was knowledge (partial eta squared $=3.5 \%$ ). Marital status and educational level explained $2.5 \%$ and $1.7 \%$ variations in attitude respectively, while chronic illness had the least contribution in explaining the variations in attitude (partial eta squared=0.7\%).

Table 6: Determinants of attitude towards OTC drugs at multivariate level.

\begin{tabular}{|c|c|c|c|}
\hline Variable & F & P-Value & Partial Eta Squared \\
\hline Knowledge & 21.3 & $<0.0001$ & 0.035 \\
\hline Marital Status & 5.04 & 0.002 & 0.025 \\
\hline Educational level & 9.84 & 0.002 & 0.017 \\
\hline Chronic illness & 4.27 & 0.039 & 0.007 \\
\hline Gender & 1.6 & 0.206 & 0.003 \\
\hline
\end{tabular}

\section{Discussion}

In the present study, most of the respondents were aware that self-medication with OTC drugs should only be practiced to treat minor diseases and injuries. This was inconsistent with a Nepalese study that reported only $12 \%$ of respondents were aware of the use of OTC drugs [17].

The knowledge of the respondents concerning the caution in the use of OTC drugs during pregnancy was also satisfactory. On the contrary, respondents' knowledge on the use of OTC drugs during breastfeeding and in elderly people was poor. Similar to pregnant women and young children, the community should be chary during the use of medicines by lactating mothers and elderly as the later are also prone to drug-related problems. However, a different finding was reported in a previous study in Eritrea in which more than $60 \%$ of the respondents, including half of the women interviewed, responded that they did not know the contraindication of aspirin with pregnant and lactating women [11].The possible explanation for this difference in knowledge could be that the question in the earlier study was confined to Aspirin's contraindication alone or due to the influence of extensive rational drug use media campaigns that have been carried out in the last few years.

Respondents' knowledge on adverse effects of OTC drugs was below average (47.7\%). A relatively lower result was also found in a similar study conducted in India that reported only $22 \%$ [10]. In this study, in spite of the respondents' poor knowledge of adverse effects of OTC drugs, their response to a question addressing 'what one should do if suspected adverse effect(s) is/are seen' was adequate. Most of the respondents answered that one should not continue taking the drug if any adverse effect(s) is/are seen and one should report to doctor or pharmacist if he/she encountered any adverse effect(s).

Broadly speaking, the descriptive analysis of the attitude of the respondents shows positive results. The majority of the respondents had a negative attitude towards the safety of OTC drugs, and this result can be further bolstered by the fact that most of the respondents assert that seeking advice from physicians is necessary before using these drugs. In simpler words, the respondents think that self-medication, if only practiced appropriately, is safer. A negative attitude towards the safety of self-medication with OTC drugs was also observed in studies conducted in India [21], Malaysia [22], Lebanon [23], and Northern Ireland [24]. But a study conducted in the neighboring country, Ethiopia, revealed an opposite attitude where $62.6 \%$ of the interviewees believed that non-prescription drugs are safe [13]. Positive perception with regard to the safety and effectiveness of OTC medicines was also extracted from a case study in Tanzania [25]. Furthermore, in the current study, twothird of the respondents believed that they better choose not to 
take OTC drugs when they feel ailments, and similar attitude was reported by Gladson et. al. [26].

The attitude of the respondents towards adverse effects, overdosing, storage requirements of liquid preparation, and the use of OTC drugs during pregnancy was also in a positive direction. On the other hand, their attitude in drug-drug interaction was relatively poor. Admittedly, most of the times knowledge about drug interactions requires deeper understanding, and as knowledge can influence the attitude of the public, this might be one reason for the above result. Several studies conducted among health science students - who are generally assumed to have better awareness about medicines - even disclosed discouraging results regarding drug interactions $[27,28]$. Similarly, coadministration of non-prescription drugs was found to be the main concern in an Ethiopian and Indian studies [13,29]. Taking the respondents' attitude into consideration, special attention should be paid to patients with co-morbidities who are on regular prescription medicines, as lack of awareness might possibly lead to major and even fatal adverse events. Azhar et al. also found a noteworthy result in which half of the participants, who were on regular prescription medications and consumed OTC drugs, were unsure or disagreed that there can be potential drug interactions between the two drugs [22].

Conceptually, as they have better exposure towards medicines, patients with chronic illness are expected to have greater awareness than those without chronic illness. Despite this commonly held assumption, respondents without chronic illness were found to have a higher significant attitude score. Truth to the nature that patients with co-morbidities are susceptible to untoward drug outcomes due to inappropriate use, intervention is required to heighten their attitude thereby assuage associated problems.

In the present study, knowledge of the respondents was the main contributor of the attitude, and respondents with above average knowledge got higher attitude score. Accordingly, by raising the awareness of the respondents, the major portion of the respondents' attitude could be increased positively. A study conducted among Nigerian pregnant women revealed a similar significant association between knowledge and attitude of the respondents [20].

\section{Conclusion and Recommendation}

Overall, the knowledge and attitude of the respondents towards OTC drugs was satisfactory except their knowledge on the use of OTC drugs in elderly and lactating women, and their attitude towards drug interactions. Respondents' educational level, knowledge, marital status, and chronic illness were found to significantly affect their attitude towards self-medication with OTC drugs. Hence, efforts should be made to raise awareness regarding self-medication in special populations and possible drug interactions, to minimize self-medication related harms. Pharmacists, as well as other health care professionals, would be able to play a major role to overcome these identified issues.

\section{Ethics Approval and Consent to Participate}

Administrative and ethical approval has been granted by the Asmara College of Health Sciences research ethical clearance committee and Ministry of health - health research proposal review and ethical clearance committee. Study participants were informed about the objective of the study and written informed consent was obtained from each respondent. All the information obtained was and will be held confidential and it was and will be used only for this study's purpose.

\section{Data Availability}

The complete dataset used and/or analyzed during the current study are available from the corresponding author and can be accessed upon a reasonable request.

\section{Conflict of Interest}

The authors declare that there is no conflict of interest regarding the publication of this paper.

\section{Acknowledgments}

We would like to forward our sincere gratitude to the experts who were enrolled in the face and content validity of the questionnaire. We owe our thanks to managers of the selected community pharmacies for allowing us to use their space to interview study participants.

\section{References}

1. WHO (2000) WHO Drug Information 14: 76.

2. Shankar P, P Partha, N Shenoy (2002) Self-medication and nondoctor prescription practices in Pokhara valley Western Nepal a questionnaire-based study. BMC Fam Pract 3(17): 7.

3. WHO (1998) The role of the pharmacist in self-care and self-medication Report of the 4th WHO Consultive Group on the role of the pharmacist. Geneva World Health Organization.

4. Hardon A, S Vander Geest (1987) Hazards of self-medication. World Health Forum.

5. Bradley CP, C Bond (1995) Increasing the number of drugs available over the counter arguments for and against. Br J Gen Pract 45(399): 553-556.

6. Hughes L, C Whittlesea, D Luscombe (2002) Patients' knowledge and perceptions of the side-effects of OTC medication. Journal of clinical pharmacy and therapeutics 27(4): 243-248.

7. Hughes GF (1999) Abuse/misuse of non-prescription drugs. Pharmacy World and Science 21(6): 251-255.

8. Sherazi BA (2012) Prevalence and measure of self-medication a review. J Pharm Sci Res.

9. Vidyavati SD, SA Kamarudin J, Katti SM (2016) Self-medication reasons, risks and benefits. Int J Healthc Biomed Res 4(4): 4.

10. Manohar HD, HL Manohar (2015) Impact of Knowledge and Attitude on Practices of Over-the-counter medications. IEOM Soc 10-11.

11. Gebrehiwet T, M Elias, H Fesshaye (2009) Knowledge on Commonly Used Analgesics among Pharmacy Customers. PharmaFocus 13(1): 6. 
12. Kołłątaj B (2015) The impact of medical knowledge on attitudes towards the use of OTC drugs. Pol J Public Health 125(3): 137-143.

13. Eyob T (2015) Understanding towards non-prescription medicines among Jimma town drug retail outlets' customers Ethiopia. Int J Res Med Health Sci 5(1): 2307-2083.

14. James H (2006) Evaluation of the knowledge attitude and practice of self-medication among first-year medical students. Med Princ Pract 15(4): 270-275.

15. Tesfamariam S (2019) Self-medication with over-the-counter drugs prevalence of risky practice and its associated factors in pharmacy outlets of Asmara Eritrea. BMC public health 19(1): 159.

16. Naing L, T Winn, B Rusli (2006) Practical issues in calculating the sample size for prevalence studies. Archi Orofacial Sci 1: 9-14.

17. Sharma D (2017) Knowledge and practice on over-the-counter drugs among adults of age group 20 and above residing in Chapapani-12 Pokhara Kaski Nepal. Int J Sci Rep 3(3): 79-86.

18. Bollu M (2014) Prevalence of self-medication among the pharmacy students in Guntur a questionnaire-based study. World J Pharm Pharm Sci 3: 810-826.

19. Jha N, O Bajracharya, PR Shankar (2013) Knowledge attitude and practice towards medicines among schoolteachers in Lalitpur district Nepal before and after an educational intervention. BMC Public Health 13(1): 652.

20. Oghenenioborue O B R, A Otovwe, O S Uju (2016) Knowledge Attitude and Use of Non-Prescription Drugs Among Pregnant Women in Okwe General Hospital Asaba Delta State Nigeria. European Journal of Pharmaceutical and Medical Research 3(11): 101-110.
21. Aishwaryalakshmi K (2012) Assessment of Knowledge Perception and Attitudes on Medications in General Population. Int J Community Pharmacy 5: 6-13.

22. Azhar MIM (2013) Self-medication awareness and attitude among Malaysian urban population. International Journal of Collaborative Research on Internal Medicine \& Public Health 5(6): 436.

23. Khalifeh M, N Moore, P Salameh (2018) Social Knowledge and Attitude toward Over-the-Counter Drug Use. American Journal of Clinical Medicine Research 6(2): 35-40.

24. Wazaify M (2005) Societal perspectives on over the counter (OTC) medicines. Family practice 22(2): 170-176.

25. Justin Temu M, D Mwambete, D Nyaki (2010) Public knowledge, attitude, and perception of over-the-counter medicines Case study in Dar es Salaam region Tanzania. East African journal of public health $7(4)$

26. Monjeza GLU (2013) People's knowledge attitude and practices about self-medication and its implications in Ilala Municipality Dar es Salaam. Muhimbili University of Health and Allied Sciences.

27. Patil SB (2015) Self-medication Awareness and Attitude among undergraduate medical students in a tertiary care medical college Dhule. National Journal of Community Medicine 6(2): 198-202.

28. Mehta RK, S Sharma (2015) Knowledge attitude and practice of selfmedication among medical students. 20(49): 65-73.

29. Ahmad A (2015) Evaluation of knowledge attitude and practice about self-medication among rural and urban north Indian population. Int J Pharm Clin Res 7(5): 7. 